\title{
Correction to: Effects of nitrogen addition on DOM-induced soil priming effects in a subtropical plantation forest and a natural forest
}

Yuexin Fan ${ }^{1,2} \cdot$ Xiaojian Zhong ${ }^{1,2} \cdot$ Teng-Chiu Lin $^{3} \cdot$ Maokui Lyu ${ }^{2} \cdot$ Minhuang Wang ${ }^{2} \cdot$ Weifang Hu ${ }^{2} \cdot$ Zhijie Yang $^{1,2}$. Guangshui Chen ${ }^{1,2} \cdot$ Jianfen Guo ${ }^{1,2} \cdot$ Yusheng Yang ${ }^{1,2,4}$

Published online: 3 January 2020

(C) Springer-Verlag GmbH Germany, part of Springer Nature 2020

Correction to: Biology and Fertility of Soils

https://doi.org/10.1007/s00374-019-01416-0

The publisher regrets that the equation within the "Calculations of soil priming effect" section and Fig. 2 where incorrectly presented in the original version of this article.

The online version of the original article can be found at https://doi.org/ 10.1007/s00374-019-01416-0

Jianfen Guo

jfguo@fjnu.edu.cn

$\bowtie$ Yusheng Yang

geoyys@fjnu.edu.cn

1 State Key Laboratory for Subtropical Mountain Ecology of the Ministry of Science and Technology and Fujian Province, Fujian Normal University, Fuzhou 350007, China

2 School of Geographical Sciences, Fujian Normal University, Fuzhou 350007, China

3 Department of Life Science, National Taiwan Normal University, Taipei 11677, Taiwan

4 Institute of Geography, Fujian Normal University, Fuzhou 350007, China 
The equation below should read:
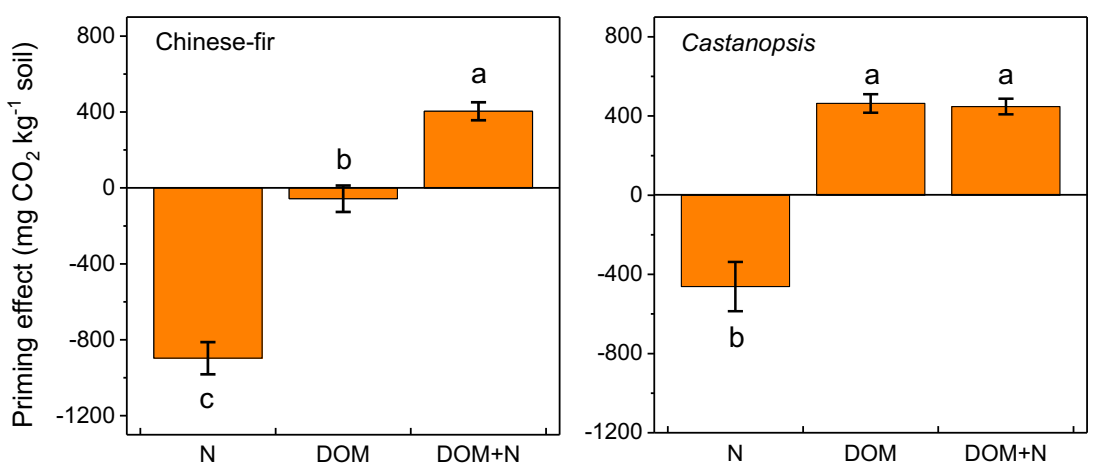

Fig. 2 Soil priming effect of the Chinese-fir and Castanopsis forests under different treatments. Values are means $\pm \mathrm{SD}(\mathrm{n}=3)$. Treatments are control, nitrogen addition $(\mathrm{N})$, leaf-derived dissolved organic matter addition (DOM), and leaf-derived dissolved organic matter plus $\mathrm{N}$ addition (DOM+N). Different letters indicate statistical significance at $\alpha=0.05$

$P_{\text {DOM }}=\left(\delta^{13} \mathrm{C}_{\text {sample }}-\delta^{13} \mathrm{C}_{\text {control }}\right) /\left(\delta^{13} \mathrm{C}_{\text {DOM }}-\delta^{13} \mathrm{C}_{\text {control }-\mathrm{S}}\right)$

The original article has been corrected.

The figure 2 should be presented as follows: 